\title{
UMIDADE DO SOLO NA ZONA RADICULAR DO MARACUJAZEIRO CULTIVADO SOB IRRIGAÇÃO LOCALIZADA ${ }^{1}$
}

\author{
VALDEMÍCIO F. SOUSA ${ }^{2}$, MARCOS V. FOLEGATTI ${ }^{3}$, JOSÉ A. FRIZZONE ${ }^{4}$, \\ RODRIGO A. L. CORREA ${ }^{5}$, THALES V. A. VIANA ${ }^{6}$
}

\begin{abstract}
RESUMO: O objetivo deste trabalho foi avaliar o efeito de níveis de irrigação aplicados por gotejamento no perfil de umidade do solo na zona de concentração radicular do maracujazeiro-amarelo (Passiflora edulis Sims f. flavicarpa Deg). O experimento foi realizado no período de julho de 1999 a janeiro de 2000, no Campo Experimental da Fazenda Areão, em Piracicaba - SP (22 42'30"S e $\left.47^{\circ} 38^{\prime} 00^{\prime} \mathrm{W}\right)$. Os níveis de irrigação, aplicados por um sistema de irrigação por gotejamento, foram: $\mathrm{L}_{1}=0,25 \mathrm{~L} ; \mathrm{L}_{2}=0,50 \mathrm{~L} ; \mathrm{L}_{3}=0,75 \mathrm{~L}$, e $\mathrm{L}_{4}=1,00 \mathrm{~L}$, em que $\mathrm{L}$ é a lâmina de água média medida em lisímetros. Os níveis de irrigação influenciaram nos perfis de distribuição temporal do potencial matricial, apresentando comportamento diferenciado na oscilação e na manutenção dos teores de água na zona radicular do maracujazeiro. A aplicação de volume de água entre $1.528 \mathrm{~L}_{\text {planta }}{ }^{-1}$ ano $^{-1}\left(\mathrm{~L}_{2}\right) \mathrm{e}$ $2.117 \mathrm{~L}_{\text {planta }}{ }^{-1} \mathrm{ano}^{-1}\left(\mathrm{~L}_{3}\right)$ favoreceu perfis médios de umidade na zona radicular do maracujazeiro mais adequados, enquanto $L_{1}$ e $L_{4}$ tiveram valores de umidade abaixo e acima do valor referente à capacidade de campo, respectivamente. Valores de potencial matricial abaixo de $-0,01445 \mathrm{MPa} e$ acima de -0,00357 MPa afetam negativamente os parâmetros de produção do maracujazeiro-amarelo.
\end{abstract}

PALAVRAS-CHAVE: potencial matricial, irrigação por gotejamento, manejo de água.

\section{SOIL MOISTURE IN THE ROOT ZONE OF PASSION FRUIT TILLED UNDER DRIP IRRIGATION}

\begin{abstract}
The objective of this study was to evaluate the effect of irrigation levels in the moisture profile in the root zone concentration of yellow passion fruit (Passiflora edulis Sims f. flavicarpa Deg). The experiment was carried out in the Experimental Area at ESALQ/USP, Piracicaba, São Paulo State, Brazil (22 $42^{\prime} 30^{\prime \prime} S$ e $\left.47^{\circ} 38^{\prime} 00^{\prime \prime} \mathrm{W}\right)$. The irrigation levels were: $\mathrm{L}_{1}=0.25 \mathrm{~L} ; \mathrm{L}_{2}=0.50 \mathrm{~L} ; \mathrm{L}_{3}=0.75 \mathrm{~L}$; $\mathrm{L}_{4}=1.00 \mathrm{~L}$, which, $\mathrm{L}$ is the average water depth measure in lysimeter. The irrigation levels influenced the temporal distribution profile of matrix potential, showed different behavior in the oscillation and maintenance of water content in root zone. The water volume applied between 1,528 L plant ${ }^{-1}$ year $^{-1}$ $\left(\mathrm{L}_{2}\right)$ and $2,117 \mathrm{~L} \mathrm{plant}^{-1}$ year $^{-1}\left(\mathrm{~L}_{3}\right)$ conduced adequate moisture levels in the passion fruit root zone, while $\mathrm{L}_{1}$ and $\mathrm{L}_{4}$ presented medium values above and below of the field capacity, respectively. Matrix potential values below $-0.01445 \mathrm{MPa}$ and above $-0.00357 \mathrm{MPa}$ affect negativity the yield parameters.
\end{abstract}

KEYWORDS: matrix potential, trickle irrigation, water management.

\footnotetext{
${ }^{1}$ Extraído da Tese de doutorado do primeiro autor.

${ }^{2}$ Eng ${ }^{0}$ Agrônomo, D.Sc., Embrapa Meio-Norte, Av. Duque de Caxias, 5650, Teresina - PI, Fone: (0XX86) 225.1141, Fax: (0XX86) 225.1142,vfsousa@cpamn.embrapa.br

${ }^{3}$ Eng ${ }^{0}$ Agrônomo, D.Sc., Professor Associado, DER/ESALQ/USP, mvfolega@ carpa.ciagri.usp.br.

${ }^{4}$ Eng $^{\mathrm{o}}$ Agrônomo, D.Sc., Professor Associado, DER/ESALQ/USP, frizzone@ carpa.ciagri.usp.br.

${ }^{5}$ Eng $^{\mathrm{o}}$ Agrônomo, Mestrando em Irrigação e Drenagem, ESALQ/USP, ralcorre@ carpa.ciagri.usp.br.

${ }^{6}$ Eng ${ }^{0}$ Agrônomo, D.Sc., Professor DEA/UFC, thales@ufc.br.

Recebido pelo Conselho Editorial em: 21-7-2005

Aprovado pelo Conselho Editorial em: 9-5-2006
} 


\section{INTRODUÇÃO}

Na agricultura irrigada, o manejo de água nas culturas preconiza a determinação da necessidade hídrica, formas de aplicação de água e acompanhamento da umidade na zona radicular das plantas. O monitoramento contínuo da umidade no solo em áreas irrigadas é importante para avaliar se a água aplicada pela irrigação está prontamente armazenando-se no solo explorado pelas raízes ou está se transferindo por percolação.

Como nas demais culturas, a irrigação para o maracujazeiro promove o seu desenvolvimento, incrementa a produtividade e mantém o pomar produzindo uniformemente, em maior tempo, com frutos de boa qualidade. No entanto, por ser bastante sensível ao déficit hídrico, o maracujazeiro necessita de grande quantidade de água para o seu desenvolvimento e produção potencial (MENZEL et al., 1986; STAVELEY \& WOLSTENHOLME,1990; MARTINS, 1998; CARVALHO et al., 2000; SILVA \& KLAR, 2002; SOUSA et al., 2003).

Além da quantidade de água fornecida pela irrigação, essa deve ser aplicada com frequiência adequada a fim de manter o solo em ótimo nível de umidade para a cultura. Resultados de pesquisas obtidos por MILNE et al. (1977) mostraram que, mantendo-se teores adequados de água no solo, aumenta-se a produtividade do maracujazeiro em até 95\%. VASCONCELLOS (1994) destaca que o maracujazeiro responde bem à irrigação e que a umidade do solo é um dos fatores que mais afetam o florescimento da cultura.

Para cada situação ou tipo de solo, valores de umidade adequados devem ser determinados. De acordo com MENZEL et al. (1986), os teores de água para o maracujazeiro devem corresponder a valores de potencial matricial próximos de $-0,006 \mathrm{MPa}$, para solos arenosos, e superiores a $-0,020 \mathrm{MPa}$, para solos de textura média a argilosa. STAVELEY \& WOLSTENHOLME (1990) determinaram que o potencial de água no solo para o maracujazeiro não deve ser inferior a -0,020 MPa durante os períodos críticos de diferenciação de flores e pegamento de frutos.

Pesquisas desenvolvidas por MENZEL et al. (1986), sob condições protegidas, mostraram que o estresse hídrico no maracujazeiro afeta sensivelmente os parâmetros de crescimento da planta. Para os autores, valores de potencial matricial inferiores a $-0,01 \mathrm{MPa}$ podem limitar severamente o desenvolvimento vegetativo e o potencial produtivo, pois a produção de matéria seca é afetada muito antes do aparecimento visual dos sintomas provocados pelo déficit hídrico. Nesse caso, os autores sugerem que o adequado para maracujazeiro é promover irrigações freqüentes, de maneira a manter o solo próximo da capacidade de campo, principalmente no período de floração e frutificação.

O objetivo deste trabalho foi avaliar o efeito de diferentes níveis de irrigação aplicados por gotejamento no perfil de umidade do solo, na zona de concentração radicular do maracujazeiroamarelo.

\section{MATERIAL E MÉTODOS}

O experimento foi desenvolvido no período de julho-1999 a janeiro-2000, no Campo Experimental da Fazenda Areão, pertencente à ESALQ/USP, localizado em Piracicaba - SP, à latitude de $22^{\circ} 42^{\prime} 30^{\prime}$ 'S e longitude de $47^{\circ} 38^{\prime} 00^{\prime}$ ' W.

O clima é subtropical úmido com estiagem no inverno, a precipitação pluviométrica média anual é de $1.247 \mathrm{~mm}$, temperatura de $21,1{ }^{\circ} \mathrm{C}$, umidade relativa média de $74 \%$ e velocidade do vento de $2,2 \mathrm{~m} \mathrm{~s}^{-1}$. Para a caracterização física do solo, foram retiradas amostras nas camadas de 0,0-0,20 m e 0,20-0,40 m para análises físicas (Tabela 1) e curva de retenção de água no solo.

O plantio das mudas de maracujazeiro-amarelo foi realizado no espaçamento de $3,5 \mathrm{~m} \mathrm{x} \mathrm{4,0} \mathrm{m,}$ em covas abertas nas dimensões de $0,50 \mathrm{~m}$ de diâmetro e $0,50 \mathrm{~m}$ de profundidade. $\mathrm{O}$ sistema de 
irrigação utilizado foi gotejamento, com emissores de vazão de $4,0 \mathrm{~L} \mathrm{~h}^{-1}$ e $2,4 \mathrm{~L} \mathrm{~h}^{-1}$, dispostos em círculo, com raio médio de $0,40 \mathrm{~m}$ do caule da planta.

TABELA 1. Características físico-hídricas do solo da área experimental.

\begin{tabular}{|c|c|c|c|c|c|c|}
\hline \multirow{2}{*}{$\begin{array}{l}\text { Camada } \\
\text { (m) }\end{array}$} & $\mathrm{CC}$ & PMP & \multirow{2}{*}{$\begin{array}{c}\text { Densidade } \\
\left(\mathrm{kg} \mathrm{dm}^{-3}\right)\end{array}$} & Argila & Silte & Areia \\
\hline & & & & \multicolumn{3}{|c|}{$\left(\mathrm{g} \mathrm{kg}^{-1}\right)$} \\
\hline $0,00-0,20$ & 0,4148 & 0,3472 & 1,49 & 624,0 & 172,0 & 204,0 \\
\hline $0,20-0,40$ & 0,4193 & 0,3491 & 1,46 & 694,3 & 138,3 & 167,4 \\
\hline
\end{tabular}

CC - capacidade de campo; PMP - ponto de murcha permanente.

Os níveis de irrigação foram determinados com base na diferença entre a entrada e a saída de água, em lisímetros de drenagem $(\mathrm{L})$ contendo plantas de maracujá. Os níveis foram: $\mathrm{L}_{1}=0,25 \mathrm{~L}$; $\mathrm{L}_{2}=0,50 \mathrm{~L} ; \mathrm{L}_{3}=0,75 \mathrm{~L} ; \mathrm{L}_{4}=1,00 \mathrm{~L}$. No período de maio a julho de 1999, o manejo de água foi realizado fornecendo-se uma quantidade de água uniforme em todos os tratamentos para garantir o pegamento das mudas e o estabelecimento da cultura. A partir de agosto de 1999, as quantidades de água foram fornecidas com base nos tratamentos estabelecidos.

O acompanhamento do potencial matricial foi feito com tensiômetros instalados a $0,30 \mathrm{~m}$ do caule da planta e a 0,30 m de profundidade (camada de 0,20 - 0,40 m). As leituras nos tensiômetros foram realizadas diariamente entre 9 e 10 horas, utilizando leitor digital de punção (tensímetro). Os valores de potencial matricial $\left(\Psi_{\mathrm{m}}\right)$ foram convertidos em valores de umidade, a partir dos parâmetros do modelo [eq.(1)] descrito por GENUCHTEN (1980), obtidos por meio dos parâmetros da curva de retenção de água no solo (Tabela 2). O perfil de umidade no solo foi analisado por meio de gráficos.

$$
\theta=\theta_{\mathrm{r}}+\frac{\theta_{\mathrm{s}}-\theta_{\mathrm{r}}}{\left[1+\left(\begin{array}{ll}
\psi_{\mathrm{m}} & \alpha
\end{array}\right)^{\mathrm{n}}\right]^{\mathrm{m}}}
$$

em que,

$\theta$ - umidade à base de volume, $\mathrm{cm}^{3} \mathrm{~cm}^{-3}$;

$\theta_{\mathrm{r}}$ - umidade residual, $\mathrm{cm}^{3} \mathrm{~cm}^{-3}$;

$\theta_{\mathrm{s}}$ - umidade de saturação, $\mathrm{cm}^{3} \mathrm{~cm}^{-3}$;

$\Psi_{\mathrm{m}}$ - potencial de água no solo, $\mathrm{cm}$ de coluna de água, e

$\alpha\left(\mathrm{cm}^{-1}\right)$, m e $\mathrm{n}$ - parâmetros empíricos do modelo matemático.

TABELA 2. Valores dos parâmetros do modelo de GENUCHTEN (1980) do perfil do solo da área experimental.

\begin{tabular}{cccccc}
\hline Camada $(\mathrm{m})$ & $\theta \mathrm{r}\left(\mathrm{cm}^{3} \mathrm{~cm}^{-3}\right)$ & $\theta \mathrm{s}\left(\mathrm{cm}^{3} \mathrm{~cm}^{-3}\right)$ & $\alpha\left(\mathrm{cm}^{-1}\right)$ & $\mathrm{m}$ & $\mathrm{n}$ \\
\hline $0,20-0,40$ & 0,255 & 0,550 & 0,1572 & 0,2549 & 1,3485 \\
\hline
\end{tabular}

\section{RESULTADOS E DISCUSSÃO}

Os valores mensais dos volumes de água aplicados em cada tratamento, no período de pegamento e estabelecimento da cultura, de maio a julho-1999, não foram diferenciados (Tabela 3). Após esse período, registraram-se, nos meses subseqüentes, variações nas quantidades de água aplicadas, em que os valores aumentaram com o tempo, em resposta a maiores exigências de consumo hídrico, e durante o crescimento das plantas, com os maiores valores de março e abril-2000.

Os perfis de distribuição temporal do potencial matricial e do conteúdo de água do solo, na profundidade de 0,30 m, em função dos níveis de irrigação (Figuras 1; 2; 3 e 4), apresentaram comportamento diferenciado na oscilação e na estabilização dos valores. 
Para o nível de irrigação $\mathrm{L}_{1}$ (Figura 1), constatou-se que o potencial matricial e a umidade do solo oscilaram entre $-0,05102$ e $-0,00062 \mathrm{MPa}$, e 0,3976 e $0,5477 \mathrm{~cm}^{3} \mathrm{~cm}^{-3}$, com média de $-0,01445 \mathrm{MPa}$ e $0,4833 \mathrm{~cm}^{3} \mathrm{~cm}^{-3}$, respectivamente.

TABELA 3. Valores mensais e totais de volumes de água aplicados com irrigação por gotejamento nos respectivos níveis de irrigação.

\begin{tabular}{lrrrr}
\hline \multirow{2}{*}{ Meses } & \multicolumn{4}{c}{ Níveis de Irrigação $\left(\mathrm{L}_{\text {planta }}{ }^{-1}\right)$} \\
\cline { 2 - 5 } & $\mathrm{L}_{1}$ & \multicolumn{1}{c}{$\mathrm{L}_{2}$} & $\mathrm{~L}_{3}$ & \multicolumn{1}{c}{$\mathrm{L}_{4}$} \\
\hline maio & 68,28 & 68,28 & 68,28 & 68,28 \\
junho & 57,19 & 57,19 & 57,19 & 57,19 \\
julho & 53,84 & 53,84 & 53,84 & 53,84 \\
agosto & 64,65 & 90,90 & 117,15 & 143,40 \\
setembro & 37,83 & 84,77 & 119,35 & 153,93 \\
outubro & 38,16 & 56,07 & 73,99 & 91,91 \\
novembro & 55,24 & 94,24 & 133,24 & 172,24 \\
dezembro & 47,88 & 82,97 & 118,05 & 153,13 \\
janeiro & 92,08 & 164,17 & 236,25 & 308,33 \\
fevereiro & 82,39 & 154,05 & 225,72 & 297,39 \\
março & 113,84 & 207,75 & 301,67 & 395,59 \\
abril & 128,13 & 247,47 & 366,80 & 486,13 \\
maio & 87,25 & 166,50 & 245,75 & 325,00 \\
\hline Total & 926,76 & $1.528,20$ & $2.117,28$ & $2.706,36$ \\
\hline
\end{tabular}

$\mathrm{L}_{1}=0,25 \mathrm{~L} ; \mathrm{L}=0,50 \mathrm{~L} ; \mathrm{L}_{3}=0,75 \mathrm{~L} \mathrm{e} \mathrm{L}_{4}=1,00 \mathrm{~L}$

Inicialmente, entre os dias 15-7 e 12-8, os valores de potencial matricial e umidade do solo mantiveram-se, na maioria, acima da média, com conteúdo de água do solo próximo da capacidade de campo. Resultados semelhantes foram observados nos períodos de 12-9 a 27-9 e 26-12 a 02-2, porém com valores de potencial matricial e de umidade concentrando-se acima da capacidade de campo $\left(-0,008 \mathrm{MPa}\right.$ e $\left.0,500 \mathrm{~cm}^{3} \mathrm{~cm}^{-3}\right)$. Nos períodos de $19-8$ a $05-9$ e $04-10$ a $11-12$, os valores de potencial e de umidade do solo foram muito variados, apresentando valores geralmente abaixo da capacidade de campo e da média. Esse comportamento dos dados pode ser atribuído ao volume de água aplicado não ter sido suficiente para atender à demanda hídrica da cultura.

Para o nível de irrigação $\mathrm{L}_{2}$ (Figura 2), os valores máximos, médios e mínimos de potencial matricial e de umidade do solo foram, respectivamente: $-0,00362 \mathrm{MPa}$ e $0,5284 \mathrm{~cm}^{3} \mathrm{~cm}^{-3},-0,00926$ MPa e $0,4909 \mathrm{~cm}^{3} \mathrm{~cm}^{-3}$ e $-0,02332 \mathrm{MPa}$ e $0,4427 \mathrm{~cm}^{3} \mathrm{~cm}^{-3}$. O perfil descrito pela Figura 2 mostrou que o nível de irrigação $\mathrm{L}_{2}$ apresentou comportamento semelhante ao perfil de $\mathrm{L}_{1}$, para alguns períodos, porém, para maiores valores de potencial matricial, manteve menos variáveis os níveis de água no solo em relação a $\mathrm{L}_{1}$, inclusive, na maioria do período, acima do valor da capacidade de campo. Nesse tratamento $\left(\mathrm{L}_{2}\right)$, o volume total de água aplicado $(1.528 \mathrm{~L})$ foi quase duas vezes superior a $\mathrm{L}_{1}$, o que justifica esse comportamento do perfil de distribuição temporal da umidade.

O nível de irrigação $\mathrm{L}_{3}$ (Figura 3) apresentou perfil de distribuição mais homogêneo, comparado ao de $\mathrm{L}_{1} \mathrm{e} \mathrm{L}_{2}$. Nesse caso, os valores de potencial matricial e de umidade do solo variaram de $-0,00362$ a $-0,01199 \mathrm{MPa}$ e de 0,5284 a 0,4809 $\mathrm{cm}^{3} \mathrm{~cm}^{-3}$, com valores médios de -0,00721 MPa e $0,5062 \mathrm{~cm}^{3} \mathrm{~cm}^{-3}$, respectivamente. Esse comportamento refletiu no desenvolvimento e na produtividade da cultura $\left(44,54 \mathrm{t} \mathrm{ha}^{-1}\right)$, tal como foi observado por MARTINS (1998) e CARVALHO et al. (2000), em que os maiores rendimentos de frutos do maracujazeiro-amarelo, 35,27 e 41,30 $\mathrm{t} \mathrm{ha}^{-1}$, respectivamente, foram obtidos com quantidades de água próximas da aplicada nas plantas do tratamento $\mathrm{L}_{3}$. 

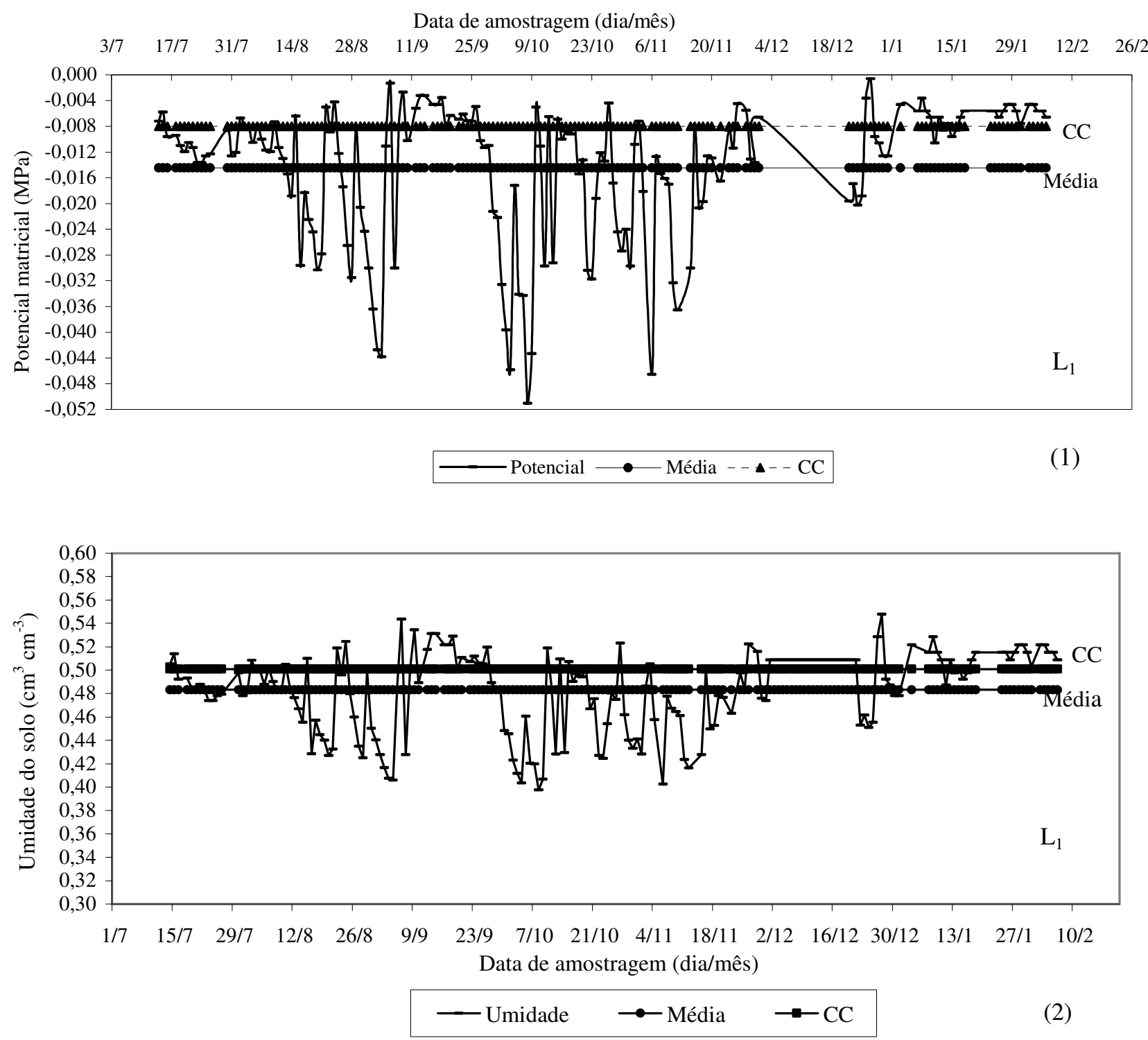

FIGURA 1. Variação do potencial matricial (1) e da umidade do solo (2) para o nível de irrigação $\mathrm{L}_{1}$.

Quanto ao nível de irrigação $\mathrm{L}_{4}$ (Figura 4), constataram-se os maiores valores médios de potencial matricial $(-0,00357 \mathrm{MPa})$ e de umidade do solo $\left(0,5322 \mathrm{~cm}^{3} \mathrm{~cm}^{-3}\right)$ com pequenas oscilações, porém bem próximos dos valores médios e superiores à capacidade de campo. Os valores de potencial e de umidade do solo apresentaram freqüência, respectivamente, entre $-0,00772$ e $-0,00122 \mathrm{MPa}$, e 0,5023 e $0,5386 \mathrm{~cm}^{3} \mathrm{~cm}^{-3}$.

Os perfis de distribuição temporal da água, na zona radicular, e os valores médios de potencial matricial de -0,01445 $\mathrm{MPa},-0,00926 \mathrm{MPa},-0,00721 \mathrm{MPa}$ e $-0,00357 \mathrm{MPa}$ para $\mathrm{L}_{1}, \mathrm{~L}_{2}, \mathrm{~L}_{3}$ e $\mathrm{L}_{4}$, respectivamente, indicam que as plantas de maracujazeiro, sob os níveis de irrigação $\mathrm{L}_{1}$ e $\mathrm{L}_{4}$, se desenvolveram, respectivamente, sob menores e maiores umidades do solo. Para MENZEL et al. (1986), plantas do maracujazeiro desenvolvidas sob estresse hídrico moderado e potencial matricial inferior a -0,01 MPa podem limitar sensivelmente o crescimento vegetativo e a capacidade produtiva. O mais adequado é manter o perfil de umidade do solo próximo da capacidade de campo, principalmente no período da floração. Para STAVELEY \& WOLSTENHOLME (1990), o potencial de água no solo para a cultura do maracujazeiro deve ser superior a $-0,02 \mathrm{MPa}$ e, durante os períodos 
críticos de diferenciação de flores e pegamento de frutos é recomendado potencial matricial não inferior a -0,015 MPa.
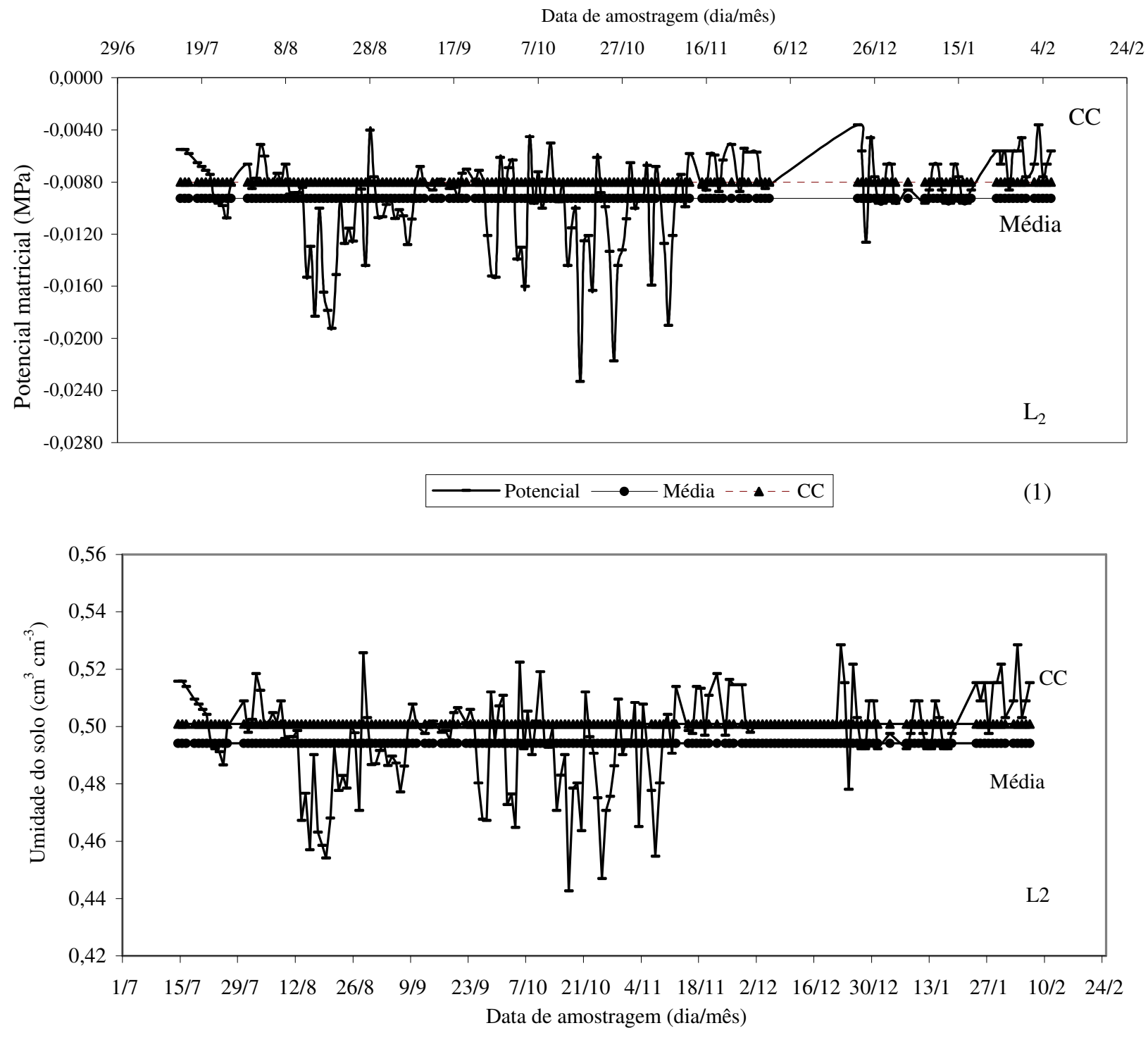

$\longrightarrow$ Umidade $\rightarrow$ Média $\rightarrow$ CC

FIGURA 2. Variação do potencial matricial (1) e da umidade do solo (2) para o nível de irrigação $\mathrm{L}_{2}$. 

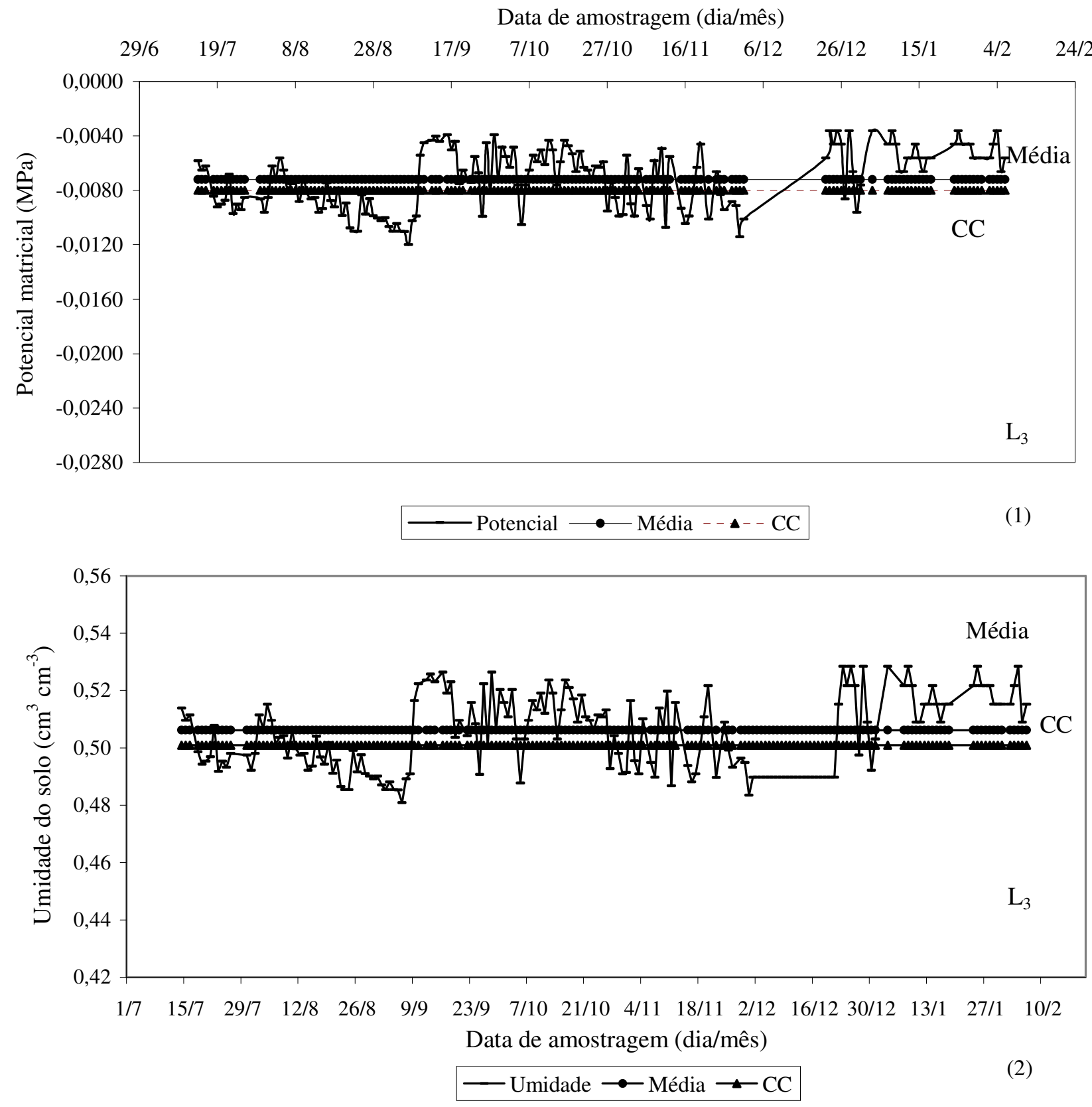

FIGURA 3. Variação do potencial matricial (1) e da umidade do solo (2) para o nível de irrigação $\mathrm{L}_{3}$. 

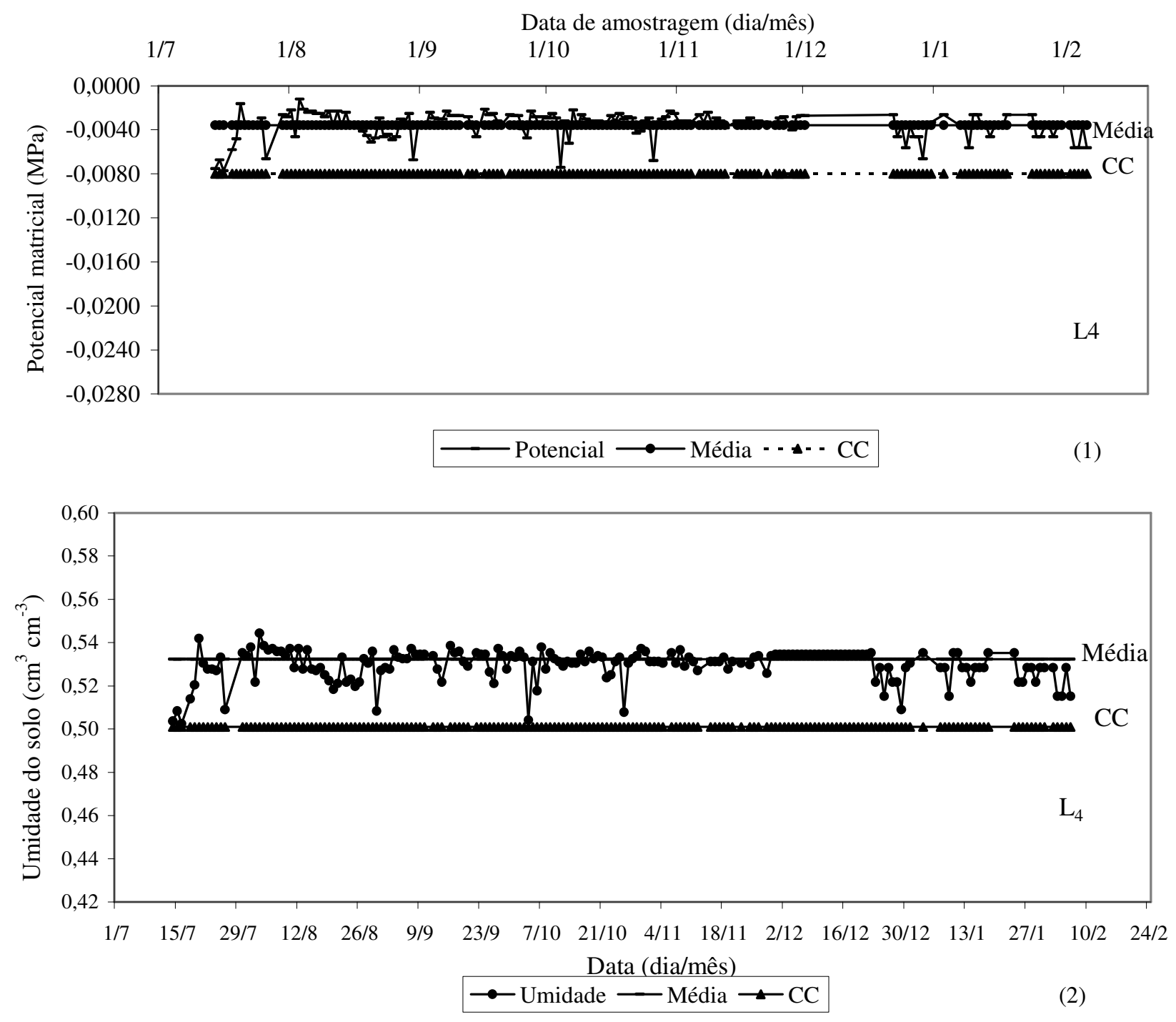

FIGURA 4. Variação do potencial matricial (1) e da umidade do solo (2) para o nível de irrigação $\mathrm{L}_{4}$, durante a condução do experimento.

Comparativamente aos comportamentos da cultura apresentados por MENZEL et al. (1986) e STAVELEY \& WOLSTENHOLME (1990), as plantas de maracujazeiro dos tratamentos $\mathrm{L}_{2}$ e $\mathrm{L}_{3}$ foram desenvolvidas sob níveis adequados de água no solo, pois $\mathrm{L}_{1} \mathrm{e} \mathrm{L}_{4}$ tiveram valores de umidade, na maior parte do tempo, abaixo e acima da capacidade de campo, respectivamente, sendo que $\mathrm{L}_{4}$ manteve esse perfil com maiores umidades, com muita freqüência durante o período avaliado. Essa distribuição temporal da umidade na zona radicular do maracujazeiro influenciou sensivelmente nos parâmetros de produção no primeiro ano, pois os maiores valores de produtividade comercial foram obtidos com a aplicação de $1.528 \mathrm{~L}_{\text {planta }}{ }^{-1}$ ano $^{-1}\left(\mathrm{~L}_{2}\right)\left(29,15 \mathrm{t} \mathrm{ha}^{-1}\right)$ e $2.117 \mathrm{~L}_{\text {planta }}{ }^{-1}$ ano $^{-1}\left(\mathrm{~L}_{3}\right)$ $\left(31,49 \mathrm{tha}^{-1}\right)$, enquanto os menores valores, 23,92 $\mathrm{tha}^{-1} \mathrm{e} \mathrm{24,43} \mathrm{tha}^{-1}$, foram obtidos com as aplicações de água equivalentes a $1.528\left(\mathrm{~L}_{1}\right)$ e $2.706 \mathrm{~L}_{\text {planta }}{ }^{-1} \mathrm{ano}^{-1}\left(\mathrm{~L}_{4}\right)$, respectivamente. Esse comportamento está de acordo com MARTINS (1998), CARVALHO et al. (1999) e CARVALHO et al. (2000), que constataram maiores rendimentos de frutos comerciais do maracujazeiro-amarelo com aplicação de água entre 1.800 e $2.000 \mathrm{~L}_{\text {planta }}{ }^{-1} \mathrm{ano}^{-1}$. 


\section{CONCLUSÕES}

Os níveis de irrigação exerceram comportamento diferenciado sobre os teores de água na zona radicular do maracujazeiro.

Os volumes de água entre $1.528\left(\mathrm{~L}_{2}\right)$ e $2.117 \mathrm{~L}$ planta $^{-1} \mathrm{ano}^{-1}\left(\mathrm{~L}_{3}\right)$ foram mais eficientes na manutenção da umidade na zona radicular do maracujazeiro.

\section{REFERÊNCIAS}

CARVALHO, A.J.C. de; MARTINS, D.P.; MONNERAT, P.H.; BERNARDO, S. Produtividade e qualidade do maracujazeiro amarelo em resposta à adubação potássica sob lâminas de irrigação. Revista Brasileira de Fruticultura, Jaboticabal, v.21, n.3, p.333-7, dez. 1999.

CARVALHO, A.J.C. de; MARTINS, D.P.; MONNERAT, P.H.; BERNARDO, S. Adubação nitrogenada e irrigação no maracujazeiro amarelo. I. Produtividade e qualidade dos frutos. Pesquisa Agropecuária Brasileira, Brasília, v.35, n.6, p.1101-8, jun. 2000.

GENUCHTEN, M.T. Van. A closed-from equation for predicting the hydraulic condutivity of unsaturated soil. Soil Science Society of America Journal, Madison, v.44, p.892-98, 1980.

MARTINS, D.P. Resposta do maracujazeiro amarelo (Passiflora edulis Sins var. favicarpa Deg.) a lâminas de irrigação e doses de nitrogênio e potássio. 1998. 84 f. Tese (Doutorado em Fitotecnia) Universidade Estadual do Norte Fluminense, Campos dos Goytacazes, 1998.

MENZEL, C. M.; SIMPSON, D. R.; DOWLING, A. J. Water relations in passion fruit: effect of moisture stress on growth, flowering and nutrient uptake. Scientia Horticulturae, Amsterdam, v.29, n.3, p.239-349, 1986.

MILNE, D.L.; DE VILLIERS, E.A.; LOGIE, J.M.; BREDELL, G.S.; BERNARD, C.J.; KUHNE, F.A. Growing grasted granadilhas. Citrus and Subtropical Fruit Journal, Johannesburg, v.524, n.1, p.16-18, 1977.

SILVA, A.A.G. da; KLAR, A.E. Demanda hídrica do maracujazeiro amarelo (Passiflora edulis Sims f. flavicarpa Deg.). Irriga, Botucatu, v.7, n.3, p.185-90, 2002.

SOUSA, V.F. de; FOLEGATTI, M.V.; FRIZZONE, J.A.; CORRÊA, R.A. de L.; ELOI, W.M. Produtividade do maracujazeiro amarelo sob diferentes níveis de irrigação e doses de potássio via fertirrigação. Pesquisa Agropecuária Brasileira, Brasília, v.38, n.4, p.497-505, 2003.

STAVELEY, G.W.; WOLSTENHOLME, B.N. Effects of water stress on growth and flowering of Passiflora edulis (Sims) grafted to P. Caerulea L. Acta Horticulturae, The Hague, n.275, p.251-8, 1990.

VASCONCELLOS, M.A.S. O cultivo do maracujá doce. In: São José, A.R. (Ed.). Maracujá: produção e mercado. Vitoria da Conquista: DFZ/UESB, 1994. p.71-83. 